\title{
Prevalence of Anaemia among the Elderly in Malaysia and Its Associated Factors: Does Ethnicity Matter?
}

\author{
Muslimah Yusof (D), ${ }^{1}$ S. Maria Awaluddin, ${ }^{1}$ Maisarah Omar, ${ }^{1}$ Noor Ani Ahmad, \\ Fazly Azry Abdul Aziz, ${ }^{1}$ Rasidah Jamaluddin, ${ }^{1}$ Tahir Aris, ${ }^{1}$ and Maw Pin Tan ${ }^{2}$ \\ ${ }^{1}$ Institute for Public Health, National Institute of Health, Ministry of Health Malaysia, 50590 Jalan Bangsar, Kuala Lumpur, Malaysia \\ ${ }^{2}$ Division of Geriatric Medicine, Faculty of Medicine, University of Malaya, Kuala Lumpur, Malaysia
}

Correspondence should be addressed to Muslimah Yusof; muslimah_yusof@moh.gov.my

Received 22 December 2017; Revised 12 February 2018; Accepted 13 March 2018; Published 29 April 2018

Academic Editor: Linda M. Gerber

Copyright (C) 2018 Muslimah Yusof et al. This is an open access article distributed under the Creative Commons Attribution License, which permits unrestricted use, distribution, and reproduction in any medium, provided the original work is properly cited.

Introduction. Anaemia is common among the elderly, yet it remains an underresearched clinical condition. This study investigates ethnic differences in prevalence of anaemia and identifies potential factors associated with anaemia in the elderly. Methods. Data from the National Health \& Morbidity Survey (NHMS) 2015 conducted by Ministry of Health was analyzed. Haemoglobin levels were measured using point-of-care testing, HemoCue ${ }^{\circledR} \mathrm{Hb} 201+$ System $\odot$, from consenting individuals. Demographic information and other clinical information were obtained through a structured questionnaire. Descriptive and multivariate analyses were conducted and significant results were presented as adjusted odds ratio. Results. A total of 3794 participants aged 60 years and older responded to the anaemia module with a response rate of $93.7 \% .64 .0 \%$ of respondents were of Malay ethnicity, $21.6 \%$ were Chinese, $6.1 \%$ were Indians, and $8.3 \%$ were of other ethnicities. The overall prevalence of anaemia among older people was $35.3 \%$. The highest prevalence of anaemia was found among respondents of Indian ethnicity (45.5\%). The Indian (aOR: 1.72; 95\% CI 1.26-2.34) and Malay (aOR: 1.25; 95\% CI 1.04-1.49) ethnic groups were more likely to be anaemic in comparison to those of Chinese ethnicity. Anaemia in older people was also associated with increasing age, history of hospital admission, and the presence of diabetes mellitus. Conclusion. Anaemia in the elderly is associated with Indian and Malay ethnicities, increasing age, hospitalization, and diabetes. Our study has identified important information on a common condition which will guide and assist future studies in reducing the burden of anaemia.

\section{Introduction}

The World Health Organization defines anaemia as a haemoglobin level of less than $12 \mathrm{~g}$ per $\mathrm{dL}(120 \mathrm{~g}$ per $\mathrm{L})$ in women and less than $13 \mathrm{~g}$ per $\mathrm{dL}$ ( $130 \mathrm{~g}$ per $\mathrm{L}$ ) in men [1]. Anaemia was estimated to be present in one-third of the global population in 2010 [2]. Anaemia in older persons is likely to contribute significantly to the global burden of disease as it is independently associated with increased morbidity and mortality $[3,4]$. Even mild anaemia can affect the quality of life in older persons [5].

Anaemia in the older person is often unrecognized due to its nonspecific symptoms of weakness and lethargy, which are often mistaken for the ageing process. Anaemia is associated with increasing age and chronic diseases including kidney diseases and diabetes mellitus and is more common in hospitalized individuals [6]. Gaskell et al. 2008 found an association between anaemia with gender and ethnicity, with African Americans and Asians being more likely to develop anaemia than Caucasians. Different ethnicities have varying cultural or religious beliefs, which in turn influence the choices of food, especially iron-rich food such as meat [7]. A previous Malaysian study on racial variations in anaemia among pregnant mothers reported that those of Indian ethnicity were found to have a higher prevalence of anaemia compared to other ethnic groups in Malaysia. Factors associated with anaemia were not identified in this study [8].

The relationship between ethnicity and anaemia has yet to be determined within the Malaysian population. Malaysia is a multiethnic nation, where its population is comprised of three major Asian ethnic groups with a large, heterogeneous 
indigenous population. This study aims at identifying the potential differences in susceptibility to anaemia among the three major ethnic groups in Malaysia. In addition, using available demographic and medical information, we aimed to identify potential mediators of these differences. An understanding of ethnic differences will facilitate further understanding of the potential influences of cultural practices, dietary factors, and genetic differences on anaemia in older adults.

\section{Methods}

This study was conducted using data from the National Health and Morbidity Survey (NHMS) 2015, a nationwide, cross-sectional survey evaluating the overall health status, health needs, and health expenditure in the Malaysian population. It is a household survey conducted by the Institute for Public Health, Ministry of Health Malaysia in 4 yearly cycles, with the main aim of monitoring noncommunicable diseases and their risk factor burden. Data collection was carried out from March 2015 until May 2015.

Ethical approval for this study was obtained from the Medical Research and Ethics Committee (MREC), Ministry of Health, Malaysia. Written consent was obtained from all respondents. The methodology of this study has been described in the technical report of the NHMS 2015 [9]. Anaemia was included as a topic together with other common health problems among the adult population.

2.1. Population and Sampling. The geographical location was stratified into 15 states to ensure national representativeness during the sampling procedure. Multistage random selection was conducted based on enumeration blocks and living quarters provided by the Department of Statistics, Malaysia. For the purpose of this study, only data obtained from individuals aged 60 years and above were included.

2.2. Sociodemographic and Clinical Characteristics. The sociodemographic variables of age, ethnicity, education level, marital status, and household income quintiles were included in this study. Respondents were also asked whether they had been admitted to hospital over the past 12 months or received any outpatient treatment over the previous 2 weeks.

Capillary blood sample was tested for haemoglobin level using the HemoCue haemoglobinometer (HemoCue $\mathrm{Hb}$ 201+ System, Angelhom, Sweden) [10, 11]. Anaemia was defined as blood haemoglobin levels below $12 \mathrm{~g} / \mathrm{dL}$ for older women and below $13 \mathrm{~g} / \mathrm{dL}$ for older men [1]. Glucose levels were tested using Cardiochek PA. These point-of-care procedures were carried out by trained health staff. The presence of diabetes was determined based on a fasting blood glucose measurement of $6.1 \mathrm{mmol} / \mathrm{l}$ and above or random blood glucose measurement of $11.1 \mathrm{mmol} / \mathrm{l}$ and above. Respondents who were previously diagnosed as having diabetes mellitus by a physician or assistant medical officer would report themselves as "known diabetes."

2.3. Statistical Analysis. IBM SPSS Statistics for Windows, Version 21.0 software, was used for data analysis. Descriptive analysis was conducted to determine the relation between the sociodemographic distribution and anaemia according to the three main ethnic groups: Malays, Chinese, Indians, and a residual "Others" category (which included all Malaysian citizens from indigenous populations). Categorical data were compared with the Chi-squared test while age, which was a continuous variable, was compared using the one-way ANOVA test. Finally, all variables with a $p$ value of 0.20 and above were included in a multivariate logistic regression model. The first model was adjusted with all the sociodemographic variables after adjustment for age. The second model identified the relationship between ethnicity and age, diabetes status, and hospital admission. The findings were presented as adjusted odds ratios (aORs) with 95\% confidence intervals (CI), and a $p$ value $<0.05$ was considered significant.

For the sake of both clarity and brevity, this paper will henceforth refer to Malaysian citizens of Malay, Chinese, and Indian ethnicities as simply Malays, Chinese, and Indians, respectively. Malaysian citizens of other ethnicities will be referred to as "Others."

\section{Results}

The overall response rate for the survey was $86.4 \%$. Out of 3794 older Malaysian citizens, 3556 (93.7\%) consented to anaemia screening. The mean age was $68( \pm 7)$ years. The respondents consisted of $64.0 \%$ Malays, $21.6 \%$ Chinese, $6.1 \%$ Indians, and $8.3 \%$ Others. Gender proportions of the respondents were similar. The majority of the Chinese and Indians lived in urban areas while Malays and others were equally distributed between urban and rural areas. Out of the total population, $11.2 \%$ had hospital admissions in the past 12 months while $13.4 \%$ had outpatient attendances. Diabetes was present in $38.1 \%$ and was most common among the ethnic Indians. Table 1 summarizes the sociodemographic characteristics of the population according to the four groups.

Table 2 demonstrates the prevalence of anaemia by sociodemography among the elderly population. The mean ( \pm standard deviation) for haemoglobin levels for the ethnic Malays was $12.8( \pm 1.8) \mathrm{g} / \mathrm{dl}$, the ethnic Chinese 13.0 $( \pm 1.8) \mathrm{g} / \mathrm{dl}$, and the ethnic Indians $12.5( \pm 1.8) \mathrm{g} / \mathrm{dl}$. The mean haemoglobin for the overall population was $12.8( \pm 1.8) \mathrm{g} / \mathrm{dl}$. The overall prevalence of anaemia among all older persons was $35.3 \%$ (95\% CI: 33.15, 37.45). The prevalence of anaemia for Malays, Chinese, Indians, and Others was 36.9 (95\% CI: 34.0, 39.9), 31.1\% (95\% CI: 27.4, 35.1), 42.1\% (95\% CI: 33.9, 50.1 ), and $36.3 \%$ (95\% CI: $30.2,43.0)$, respectively. Univariate analyses revealed significant ethnic differences in the prevalence of anaemia. In addition, the sociodemographic factors including age, level of education, marital status, hospital admission in the previous 12 months, and diabetes all differed significantly. The prevalence of anaemia increases from $28 \%$ among men in the 60 to 64 years' age group to $64 \%$ in men aged 80 years and over. In comparison, $35 \%$ of women aged 60-64 years had anaemia while $54 \%$ of women aged 80 years and over were anaemic (Figure 1).

Multivariate analyses revealed that following adjustment for age differences, Malays were significantly more likely to be anaemic than Chinese respondents (adjusted odds ratio, 


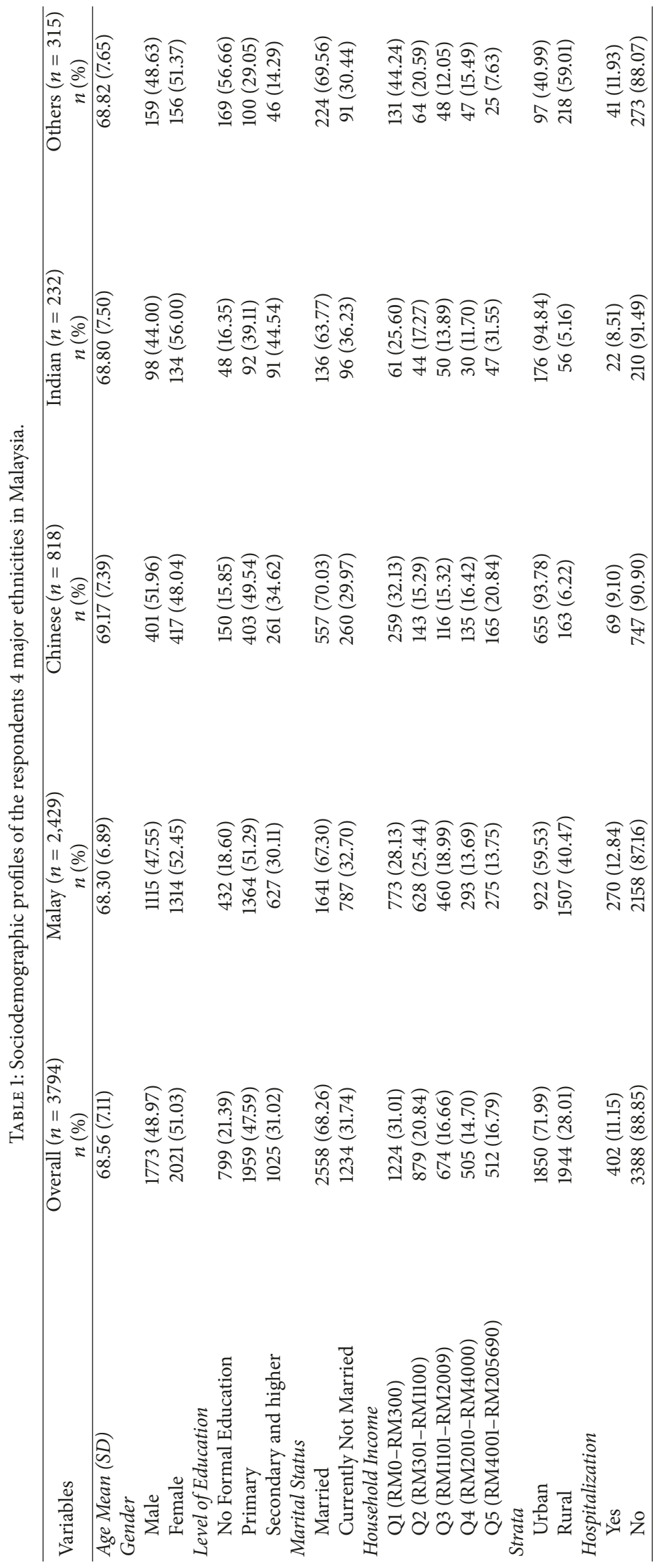




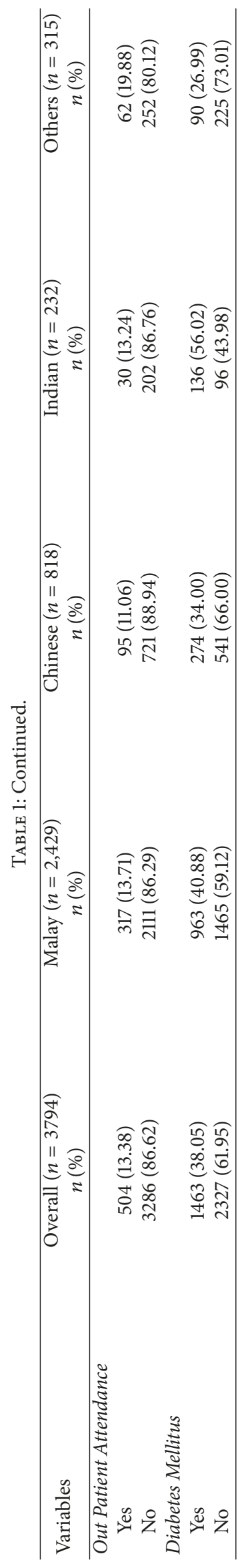




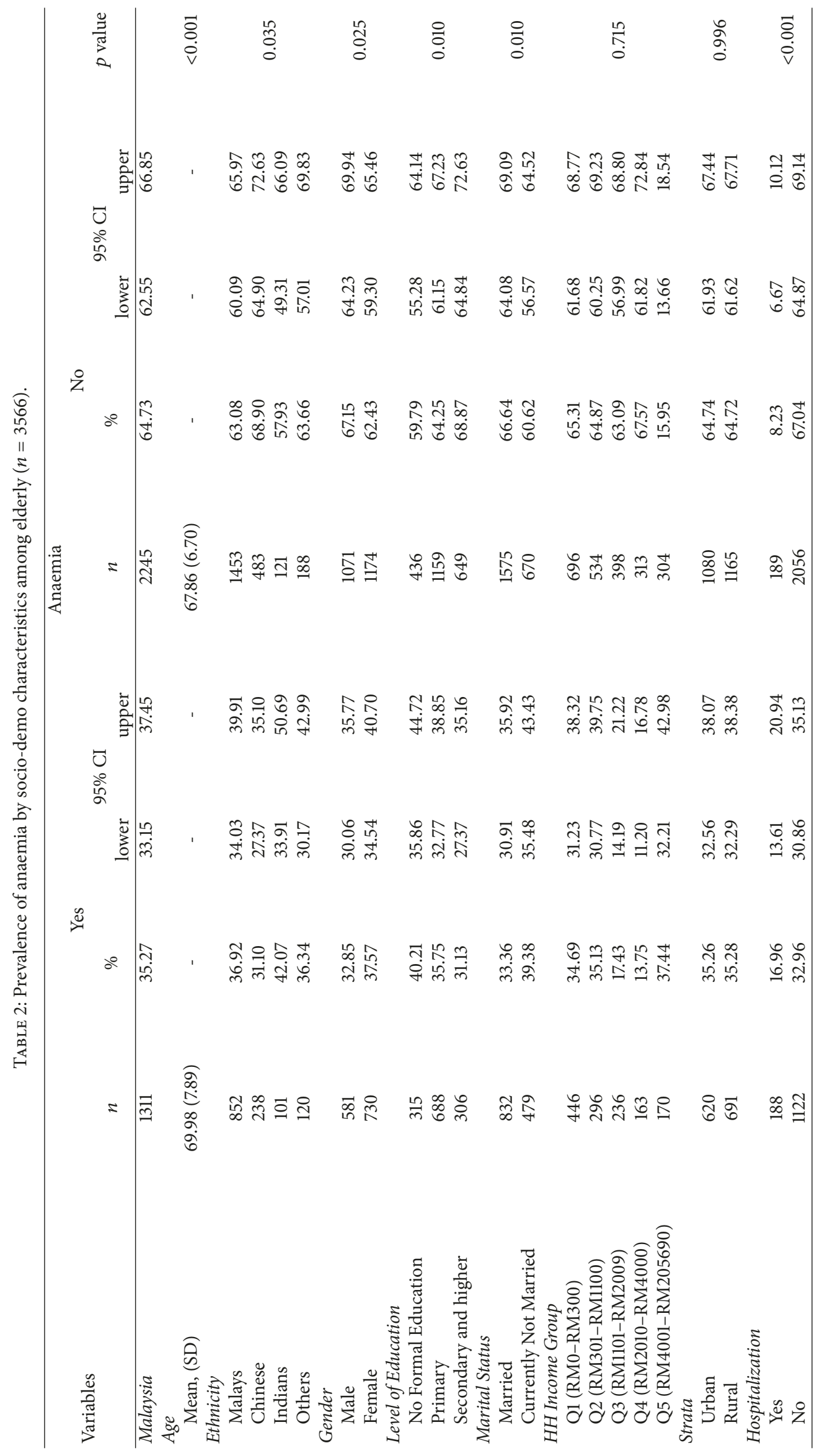




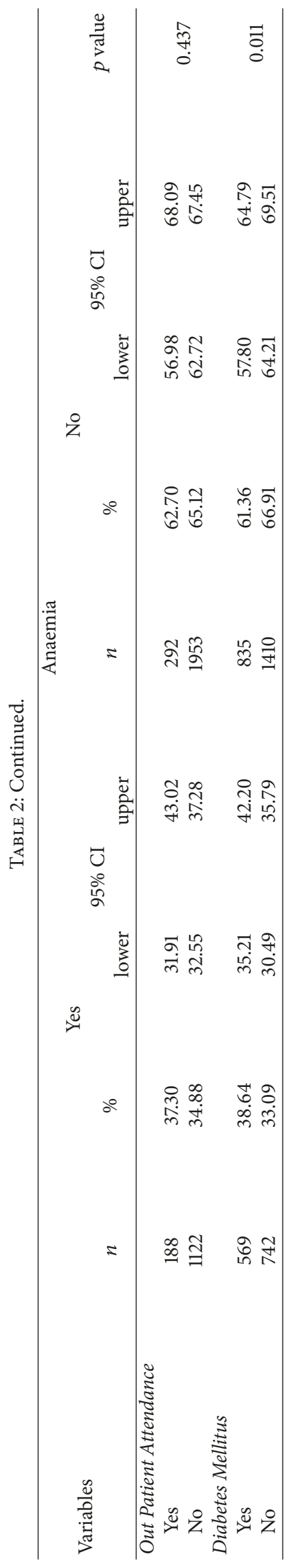




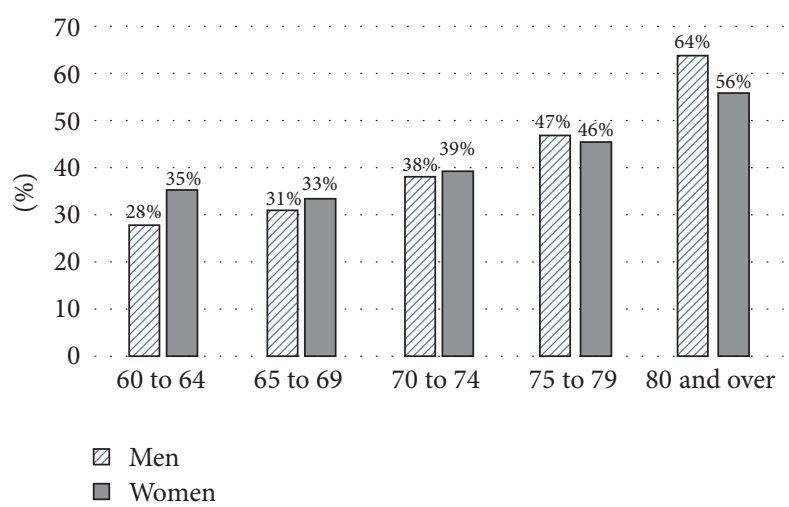

FIGURE 1: Bar chart comparing prevalence of anaemia by fiver-year age groups according to gender.

$\mathrm{aOR}=1.25 ; 95 \% \mathrm{CI}=1.04$ to 1.49 ). Indians were also significantly more likely to be anaemic than Chinese respondents after age adjustment $(\mathrm{aOR}=1.72 ; 95 \% \mathrm{CI}=1.26$ to 2.34) (Model 1). In Model 2, following additional adjustment for hospitalization and diabetes mellitus, the Malays and Indians remained more likely to be anaemic than the Chinese (Table 3).

\section{Discussion}

Utilizing data from a nationally representative cross-sectional survey, the elderly Malays and Indians were significantly more likely to have anaemia according to international criteria than the elderly Chinese. This study is continuation from the previous published article regarding anaemia in Malaysian adult population [12].

This was the first study to report ethnic differences in the prevalence of anaemia in an Asian population. Racial differences in anaemia prevalence have been reported in high income general populations or younger populations [13]. A previous study conducted in Singapore had included ethnicity as a variable in their study evaluating anaemia in patients with chronic kidney disease but found no ethnic differences in the prevalence of anaemia among the Chinese, Indian, and Malay populations [14]. However, this study was conducted among hospital patients and in a comparatively smaller population. A recent report on anaemia from the National Health and Nutritional Examination Survey (NHANES) in the United States revealed a much higher prevalence of anaemia among non-Hispanic blacks [15]. Anaemia in older adults, therefore, remains poorly characterized, with much more work being required before effective measures can be considered for this condition, which is likely to pose an increasing burden on society with the rapidly ageing population worldwide.

The prevalence of anaemia in the different ethnic groups in our older population was comparatively higher than that reported in the published literature. A previous systematic review had suggested an overall prevalence of $12 \%$ among community-dwelling older adults [6]. The prevalence of $31 \%$ to $46 \%$ among the different ethnic groups in Malaysia appears to be many folds higher than that reported in studies involving other older populations $[16,17]$. The apparently higher prevalence of anaemia in our older population is therefore likely to reflect the higher prevalence of comorbidities especially diabetes mellitus and chronic kidney disease in our older population $[9,18]$. In addition, the Asian ethnic groups are also far more likely to have inherited haemoglobinopathies such as thalassaemia minor which may escape clinical detection throughout life and with no known adverse effects on life expectancy [19]. The exact contribution of thalassaemia traits to anaemia in our population is yet to be established.

The higher prevalence of anaemia among our older Indian population is supported by the findings of a study on anaemia prevalence conducted within the Indian subcontinent [20], which utilized the hospital database at a single centre. Their estimated prevalence of over $50 \%$ for women of all ages and men aged over 60 years is, however, not comparable to that of our community-based sample. Normocytic anaemia was commonest among their older population suggesting that anaemia could be due to causes other than iron deficiency in their older population. Nevertheless, iron deficiency anaemia has been previously found to be associated with Indian ethnicity as many Hindu devotees are traditionally vegetarians $[21,22]$. The bioavailability of vitamin B12 is known to be poor in the traditional Indian vegetarian diet [23].

In terms of nutritional deficiency, in addition to cultural beliefs and religious prohibitions, socioeconomic factors also contribute to nutritional intake as a high socioeconomic status is associated with food diversity and a healthier diet [24]. In general, anaemia is patterned by socioeconomic factors especially by household income whereby those living in the lowest wealth quintiles were found to have $25 \%$ higher than among those from the highest quintile [25]. A study done in China reported that a relatively lower risk of anaemia was associated with greater health awareness and a higher household income status [26]. A Singaporean study observed a higher risk of developing iron deficiency anaemia among non-Chinese ethnicities [27]. The aetiology underlying the ethnic differences in anaemia in our population could not be established in this cross-sectional survey. Previous reports have suggested that anaemia in older adults are more likely to occur due to chronic illness than nutritional deficiencies [28]. Following adjustment for hospitalization and the presence 


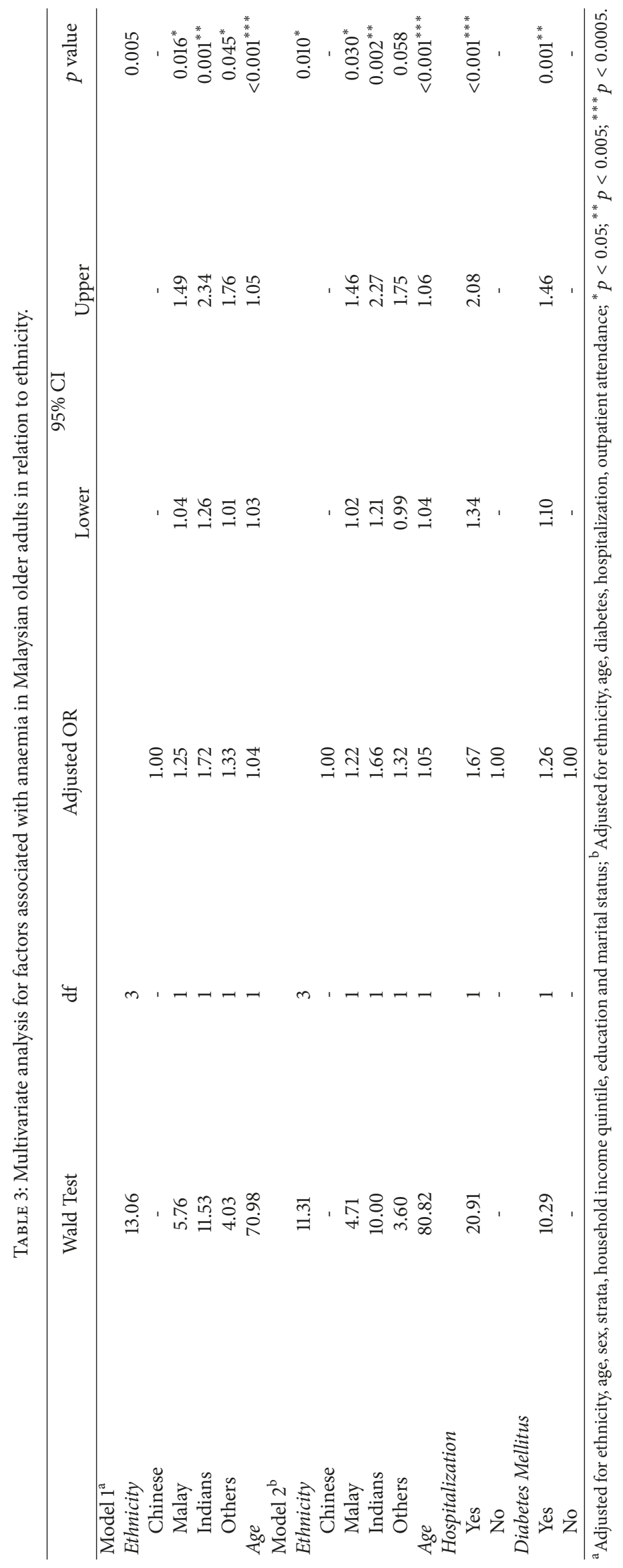


of diabetes in our study, however, the ethnic differences in anaemia status remained statistically significant. There is an established relationship between B12 deficiency and diabetes mellitus [27]. In addition, we consider hospitalization as a marker of frailty and medical illness and diabetes as an indicator of chronic disease [29]. Anaemia may also be more likely among those with diabetes due to the increased risk of renal disease $[30,31]$. Both Malay and Indian ethnicities were strong independent risk factors for anaemia after the above adjustments, suggesting that the increased risk of anaemia among Indians is not explained by hospitalization nor diabetes. In a previous study involving diabetics in California, the presence of chronic disease accounted for onethird of cases of anaemia and ethnicity remained an independent predictor for anaemia in their diabetic population, for which underlying factors were yet to be established [32]. The absence of any mediators of anaemia in our study population therefore brings into question the likelihood of genetic predilection for anaemia. However, the prevalence of the commonest inherited blood dyscrasia among Asians, betathalassemia, has been evaluated among large populations in both China and India with similar prevalence of betathalassaemia status of around 3\% [33, 34].

As this was a cross-sectional survey, causative relationships could not be established. Haemoglobin in this study was based on point-of-care screening which may lead to a falsely high haemoglobin result by $0.1 \mathrm{~g} / \mathrm{dL}$ [35]. However, point-of-care screening provides fast and mostly valid results and was felt to be the most appropriate choice to allow for measurement of haemoglobin in remote settings [36]. As a consequence of our choice of measurement tool, there were no associated measurements on cell counts, mean corpuscular volume, haematocrit, or iron studies available. Therefore, it was not possible to determine the type of anaemia in our study population. In addition, as anaemia was assessed as part of a larger national health survey, it was not possible to also accurately assess coexisting medical illness, renal function, or use of medications in our study population. The low percentage of Indian in our population may reduce the accuracy of detection of anaemia in our population. Future studies should now evaluate further the rationale behind the increased risk of anaemia among the older Indians, the relatively higher prevalence of anaemia overall among our older population compared to other population studies, and aim to identify strategies to lower the burden of anaemia among our population, possibly through appropriate chronic disease management. To improve the characterization of anaemia in the ethnic Indians, a stratified sampling method should also be considered.

\section{Conclusions}

Our cross-sectional survey conducted in a multiethnic Asian population has found that both Indian and Malay ethnicities were independent predictors of the presence of anaemia. The differences in prevalence of anaemia in both ethnic Malays and Indians compared to the ethnic Chinese remain significant after adjustment for presence of diabetes and hospitalization in the past 12 months. Our study has identified a high prevalence of anaemia among all ethnic groups, as well as potential modifiable factors to reduce the burden of anaemia among our older population. Further studies should attempt to identify the underlying causes of this common condition among our older population.

\section{Conflicts of Interest}

All authors do not have any conflicts of interest.

\section{Authors' Contributions}

All authors have participated actively in this study.

\section{Acknowledgments}

The authors wish to thank the Director General of Health Malaysia for his permission to publish this study. The authors also would like to acknowledge the NHMS steering committee for their technical support. Our appreciation is further extended to all staff involved throughout the study.

\section{References}

[1] WHO, Haemoglobin Concentrations for the Diagnosis of Anaemia And Assessment of Severity, World Health Organization, Geneva, Switzerland, 2011, http://www.who.int/vmnis/ indicators/haemoglobin.pdf.

[2] N. J. Kassebaum, R. Jasrasaria, N. Johns et al., "A systematic analysis of global anaemia burden between 1990 and 2010," Blood, vol. 381, no. 5, p. S72, 2013.

[3] E. Riva, M. Tettamanti, P. Mosconi et al., "Association of mild anemia with hospitalization and mortality in the elderly: the Health and Anemia population-based study," Haematologica, vol. 94, no. 1, pp. 22-28, 2009.

[4] M. H. Bross, K. Soch, and T. Smith-Knuppel, "Anemia in older persons," American Family Physician, vol. 82, no. 5, pp. 480-487, 2010.

[5] T. Juárez-Cedillo, L. Basurto-Acevedo, S. Vega-García et al., "Prevalence of anemia and its impact on the state of frailty in elderly people living in the community: SADEM study," Annals of Hematology, vol. 93, no. 12, pp. 2057-2062, 2014.

[6] H. Gaskell, S. Derry, R. Andrew Moore, and H. J. McQuay, "Prevalence of anaemia in older persons: systematic review," BMC Geriatrics, vol. 8, no. 1, 2008, http://bmcgeriatr.biomedcentral.com/articles/10.1186/1471-2318-8-1.

[7] R. K. Chandyo, T. A. Strand, R. J. Ulvik et al., "Prevalence of iron deficiency and anemia among healthy women of reproductive age in Bhaktapur, Nepal," European Journal of Clinical Nutrition, vol. 61, no. 2, pp. 262-269, 2007.

[8] A. C. C. Tan, E. W. K. Leong, A. C. Chua, and F. M. Moy, "Racial variations in booking haemoglobin of primigravidae in Malaysia: A prospective study," BMC Research Notes, vol. 6, no. 1, article no. 173, 2013.

[9] Institute for Public Health (IPH), National Health and Morbidity Survey 2015 (NHMS 2015), vol. I of Methodology and General Findings, Ministry of Health Malaysia, Kuala Lumpur, Malaysia, 2015.

[10] A. N. Ani, Y. U. Nadiah, D. N. Azah, A. Akmal, and A. Tahir, "Sensitivity and specificity of CardioChek ${ }^{\circledR} \mathrm{PA}$ in detecting 
individuals with abnormal cholesterol and glucose level," International Journal Biomedicine, vol. 2, no. 2, pp. 132-135, 2012.

[11] HemoCue [Internet]. [cited 2016 Dec 29]. Available from: http://www.hemocue.com/en/clinical-settings/public-health.

[12] S. M. Awaluddin, N. A. Ahmad, B. M. Naidu, M. S. Mohamad, and M. Yusof, "A Population-based anaemia screening using point-of-care in estimating prevalence of anaemia in malaysian adults: findings from a nationwide survey," Journal of Community Medicine \& Health Education, vol. 7, no. 513, pp. 2161-2711, 2017.

[13] N. A. Zakai, L. A. McClure, R. Prineas et al., "Correlates of anemia in American Blacks and Whites: The REGARDS Renal Ancillary study," American Journal of Epidemiology, vol. 169, no. 3, pp. 355-364, 2009.

[14] B. C. V. Lau, K. Y. Ong, C. W. Yap, A. Vathsala, and P. How, "Predictors of anemia in a multi-ethnic chronic kidney disease population: a case-control study," SpringerPlus, vol. 4, no. 1, article no. 233, pp. 1-9, 2015.

[15] C. H. H. Le, "The prevalence of anemia and moderate-severe anemia in the US population (NHANES 2003-2012)," PLoS ONE, vol. 11, no. 11, Article ID e0166635, 2016.

[16] T. Yildirim, A. Yalcin, V. Atmis et al., "The prevalence of anemia, iron, vitamin B12, and folic acid deficiencies in community dwelling elderly in Ankara, Turkey," Archives of Gerontology and Geriatrics, vol. 60, no. 2, pp. 344-348, 2015.

[17] V. Sgnaolin, P. Engroff, L. S. Ely et al., "Hematological parameters and prevalence of anemia among free-living elderly in south Brazil," Revista Brasileira de Hematologia e Hemoterapia, vol. 35, no. 2, pp. 115-118, 2013.

[18] M. Salman, A. H. Khan, A. S. Adnan et al., "Prevalence and management of anemia in pre-dialysis Malaysian patients: A hospital-based study," Revista da Associação Médica Brasileira, vol. 62, no. 8, pp. 742-747, 2016.

[19] J.-A. M. A. Tan, P.-C. Lee, Y.-C. Wee et al., "High prevalence of alpha- and beta-thalassemia in the kadazandusuns in east Malaysia: Challenges in providing effective health care for an indigenous group," Journal of Biomedicine and Biotechnology, vol. 2010, Article ID 706872, 2010.

[20] G. Alvarez-Uria, P. K. Naik, M. Midde, P. S. Yalla, and R. Pakam, "Prevalence and severity of anaemia stratified by age and gender in rural India," Anemia, vol. 2014, Article ID 176182, 5 pages, 2014.

[21] A. Rammohan, N. Awofeso, and M.-C. Robitaille, "Addressing female iron-deficiency anaemia in india: is vegetarianism the major obstacle?” ISRN Public Health, vol. 2012, 8 pages, 2012.

[22] D. Y. Kwon and J. P. Tamang, "Religious ethnic foods," Journal of Ethnic Foods, vol. 2, no. 2, pp. 45-46, 2015.

[23] K. Shridhar, P. K. Dhillon, L. Bowen et al., "Nutritional profile of Indian vegetarian diets-the Indian Migration Study (IMS)," Nutrition Journal, vol. 13, article 55, 2014.

[24] A.-L. Mayén, P. Marques-Vidal, F. Paccaud, P. Bovet, and S. Stringhini, "Socioeconomic determinants of dietary patterns in low- and middle-income countries: A systematic review," American Journal of Clinical Nutrition, vol. 100, no. 6, pp. 15201531, 2014.

[25] Y. Balarajan, U. Ramakrishnan, E. Özaltin, A. H. Shankar, and S. V. Subramanian, "Anaemia in low-income and middle-income countries," The Lancet, vol. 378, no. 9809, pp. 2123-2135, 2011.

[26] L. Li, R. Luo, S. Sylvia, A. Medina, and S. Rozelle, "The Prevalence of anemia in central and eastern China: Evidance from the China health and nutrition survey," Southest Asian Journal of Tropical Medicine \& Public Health, vol. 46, no. 2, 2015.
[27] M. R. J. Tay and Y. Y. Ong, "Prevalence and risk factors of anaemia in older hospitalised patients," Proceedings of Singapore Healthcare, vol. 20, no. 2, pp. 71-79, 2011.

[28] S. J. Fairweather-Tait, A. A. Wawer, R. Gillings, A. Jennings, and P. K. Myint, "Iron status in the elderly," Mechanisms of Ageing and Development, vol. 136-137, pp. 22-28, 2014.

[29] G. Röhrig, W. Klossok, I. Becker, T. Benzing, and R. J. Schulz, "Prevalence of anemia among elderly patients in an emergency room setting," European Geriatric Medicine, vol. 5, no. 1, pp. 3-7, 2014.

[30] V. F. Feteh, S.-P. Choukem, A.-P. Kengne, D. N. Nebongo, and M. Ngowe-Ngowe, "Anemia in type 2 diabetic patients and correlation with kidney function in a tertiary care sub-Saharan African hospital: A cross-sectional study," BMC Nephrology, vol. 17, no. 1, article no. 29, 2016.

[31] L. P. Corona, Y. A. D. O. Duarte, and M. L. Lebrão, "Prevalence of anemia and associated factors in older adults: Evidence from the SABE Study," Revista de Saúde Pública, vol. 48, no. 5, pp. 723-731, 2014.

[32] A. T. Ahmed, A. S. Go, E. M. Warton, M. M. Parker, and A. J. Karter, "Ethnic differences in anemia among patients with diabetes mellitus: The Diabetes Study of Northern California (DISTANCE)," American Journal of Hematology, vol. 85, no. 1, pp. 57-61, 2010.

[33] X. Xu, C. Liao, Z. Liu et al., "Antenatal screening and fetal diagnosis of $\beta$-thalassemia in a Chinese population: Prevalence of the $\beta$-thalassemia trait in the Guangzhou area of China," Human Genetics, vol. 98, no. 2, pp. 199-202, 1996.

[34] D. Mohanty, R. B. Colah, A. C. Gorakshakar et al., "Prevalence of $\beta$-thalassemia and other haemoglobinopathies in six cities in India: a multicentre study," Journal of Community Genetics, vol. 4, no. 1, pp. 33-42, 2013.

[35] T. Srivastava, H. Negandhi, S. B. Neogi, J. Sharma, and R. Saxena, "Methods for hemoglobin estimation: a review of what works," Journal of Hematology \& Transfusion, vol. 2, no. 3, p. 1028, 2014.

[36] C. Briggs, J. Carter, S.-H. Lee, L. Sandhaus, R. Simon-Lopez, and J.-L. Vives Corrons, "ICSH Guideline for worldwide pointof-care testing in haematology with special reference to the complete blood count," International Journal of Laboratory Hematology, vol. 30, no. 2, pp. 105-116, 2008. 


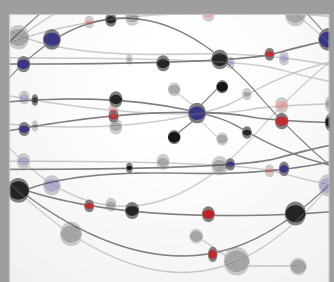

The Scientific World Journal
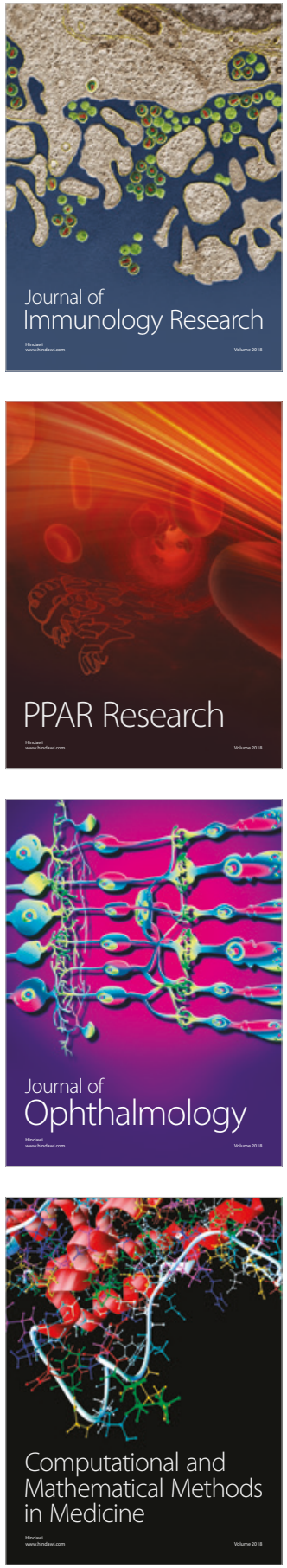

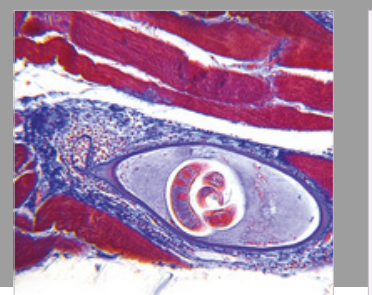

Gastroenterology Research and Practice

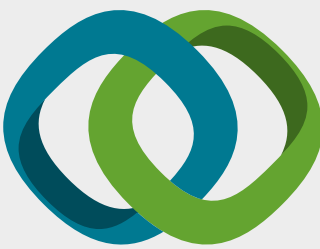

\section{Hindawi}

Submit your manuscripts at

www.hindawi.com
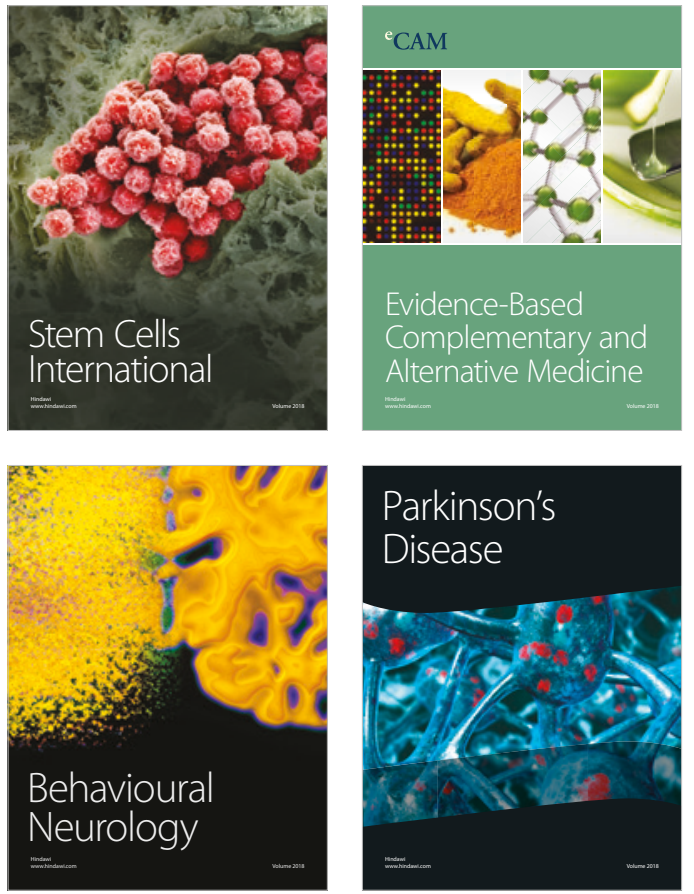

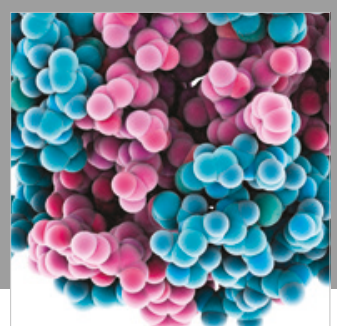

ournal of

Diabetes Research

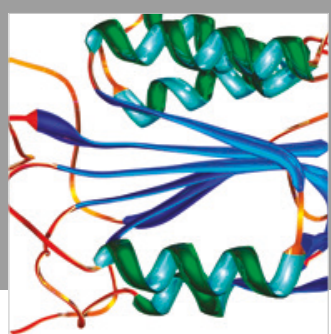

Disease Markers
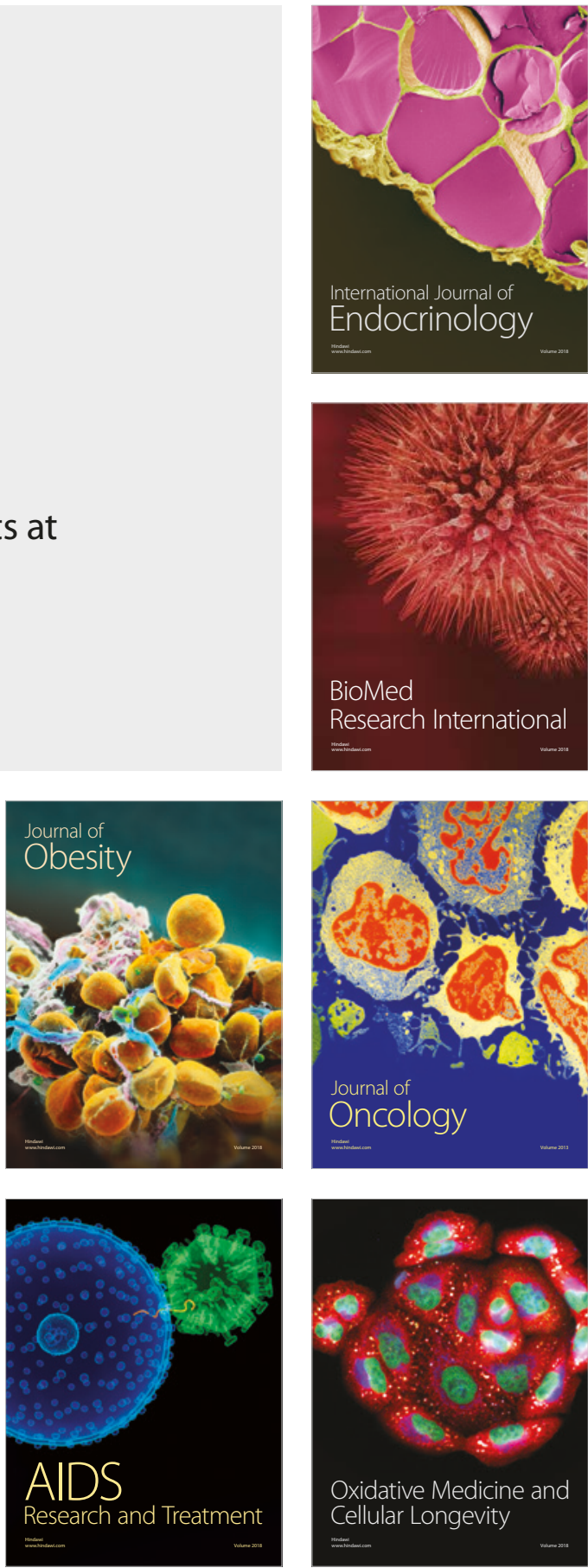